\title{
Magnetic Leakage Internal Detection Device and Series-Parallel Detection Method for Small Diameter Ferromagnetic Spiral Heat Exchanger Tubes
}

\author{
Wei CUI, Yuhang ZHANG, Ziming FENG, Chaodong TAN, Decheng LENG, Qiang ZHANG
}

\begin{abstract}
Based on the calculation of magnetic circuit of the detection probe, this article designs a kind of magnetic leakage detection device and series-parallel detection method of small diameter spiral heat exchange tube to realize the safety detection of small diameter spiral heat exchange tube. The detection device includes a detection probe and a probe drive mechanism, which drives the detection probe to move in the spiral heat exchange tube. The detection probe includes an intermediate connector, a magnetizer which is arranged coaxially at both ends of the intermediate connector in turn, a steel ball support body and an end connector. The designed detection probes are mixed in series and parallel, and multiple detection probes are put together in series to be placed in a spiral heat exchange tube to form a group of detection probes in series. Then, multiple groups of detection probes in series are placed in each spiral heat exchange pipe, forming a series-parallel combination, which can detect multiple spiral heat exchange pipes at the same time and improve the detection efficiency greatly.
\end{abstract}

Keywords: detection method of series and parallel connection; ferromagnetic spiral heat exchange tube; magnetic leakage internal detection; small diameter

\section{INTRODUCTION}

The spiral tube heat exchanger, which was first developed by Linde Company in Germany in 1895 , is a new type of heat exchanger with high heat transfer coefficient. Compared with the traditional tube heat exchanger, it has the advantages of high heat transfer efficiency, compact structure, high operating pressure in tube, increased length of heat exchanger tube, increased heat exchange area per unit volume, small occupied space, etc., which makes it has a broad application prospects in petrochemical, nuclear power, metallurgy and other fields [1-6]. Literature [2] presents the heat transfer data of heat transfer characteristics of a helically coiled crimped spiral finned tube heat exchanger. The following conclusion is given: there is no effect of air mass flow rate on the tubeside heat transfer coefficient; the inlet-water temperature and water mass flow rate show a significant effect on the out-side heat transfer coefficient; the Colburn $\mathrm{j}$ factor and effectiveness are inversely proportional to air-side Reynolds number, but directly proportional to the water mass flow rate and inlet water temperature. Literature [3] presents the Influence of spiral pitch on the thermal behaviour of energy piles with spiral-tube heat exchanger. The energy pile with a small spiral pitch is energy-efficient and has a better applicability. The increase of the spiral pitch $(S P=0.25-2.0)$ leads to a reduction of the mean coefficients of performance $(0.77-15.52 \%)$ according to the influential factors. In the process of its service, it is subject to frequent low-cycle alternating load in the environment with mixed impurities for a long time, which easily leads to the leakage. It may lead to the material to be mixed, which will affect the normal operation of production, or even cause fire accidents.

At present, scholars at home and abroad often use acoustic method, magnetic flux leakage, eddy current, ultrasonic and other detection methods to detect and evaluate the heat exchanger straight tubes of tubular heat exchangers [7-11]. Creep damage accumulation in steel welds of boiler heat exchange tubes is evaluated using the nonlinear acoustic method and microstructural observation. For the nonlinear acoustic method, the immersion technique is used. Increased amplitudes were measured around the heat-affected zone (HAZ), which corresponded to the areas of high creep void density observed by microscopy. The nonlinear acoustic method has been confirmed to have the potential to assess the creep damage in boiler heat exchange Tubes [7]. Using the finite element software, this research group analyzed the effect of magnetic flux leakage in detecting heat exchange tubes to increase the magnetic structure. The results show that the magnetic induction intensity of leakage of magnetic field is enhanced after the magnetic structure is adopted, which is beneficial to the detection of defects [9]. The eddy current array method is used to simulate the heat exchange tube of nuclear power plant based on analytical and numerical combination methods. The results show that the test results are in good agreement with the simulation results of commercial software [10]. The torsional mode ultrasonic guided wave method was used to simulate and analyze the defects of heat exchange tube. Two different excitation modes of corner loading and torque loading are studied. The simulation results show that both excitation modes can successfully excite the $T(0,1)$ modal guided wave, and the defect location is accurate. In addition, the torsional guided wave has a greater attenuation in the bend [11].

Due to the limitation of spiral heat exchange tube structure, there is no non-destructive testing method and testing device for spiral heat exchange tube. Aiming at the universality of ferromagnetic spiral heat exchange tube, the magnetic leakage method is introduced into the detection of ferromagnetic spiral heat exchange tube in this work. Magnetic flux leakage detection is based on the high permeability of ferromagnetic materials. The ferromagnetic materials can be magnetized under the induction of external magnetic field, and the magnetic leakage field will be formed at the defects. It is widely used in the detection of petroleum and petrochemical equipment and pipelines because of its high detection reliability, easy automation and high detection efficiency [12-15]. Based on the above advantages of magnetic flux leakage method, this paper develops an internal magnetic flux leakage detection device for small diameter spiral heat exchanger tubes and a series-parallel detection method to realize the internal magnetic flux leakage detection for small diameter 
spiral heat exchanger tubes, widen the scope of existing objects, and has practical theoretical significance and wide engineering application prospects for ensuring the safe and stable operation of spiral heat exchanger.

\section{PRINCIPLE OF MAGNETIC LEAKAGE DETECTION FOR SMALL DIAMETER FERROMAGNETIC SPIRAL HEAT EXCHANGER TUBE}

During the on-line magnetic flux leakage detection of large-diameter ferromagnetic pipelines, a kind of instrument called "pipeline pigs" is often used, which uses circumferential array magnets to obtain excitation sources. The tested object of this paper is a small diameter helical heat exchanger tube with $14 \mathrm{~mm}$ inner diameter. It is required that the designed probe can pass through both straight and elbow tubes. Due to the limitation of the inner space of the tube, it is impossible to place large-sized permanent magnets in small diameter spiral heat exchanger tubes for excitation. Therefore, this work puts to use the axial magnetization method, magnetic flux leakage probe principle and the structure diagram is shown in Fig. 1. As we can see in Fig. 1, the excitation structure is composed of permanent magnet, armature and magnetic rubber rollers connected in the middle. Two cylindrical permanent magnets with opposite magnetic poles and the same direction with the axis of heat exchanger pipe are connected by intermediate magnetic rubber rollers. The middle part of the magnetic rubber rollers is narrower than the two ends, which is used to provide space for the installation of magnetic sensors and signal circuits. The magnetic rubber roller has large flexibility and small bending stiffness, so that it not only has magnetic conductivity, but also meets the passing demand of small diameter spiral heat exchanger tubes. The armature transfers the axial magnetic field into a more uniform circumferential magnetic field and leads the helical heat exchanger tube into a closed magnetic circuit. When there is defect damage in the pipe wall, the magnetic flux line will change the way due to the small permeability and large magnetoresistance of the defect, which will distort the nearby magnetic field, bend the magnetic field line and overflow a part of the magnetic field line, forming the flux leakage. At this time, the magnetic flux leakage signal will be collected through the magnetic sensor.

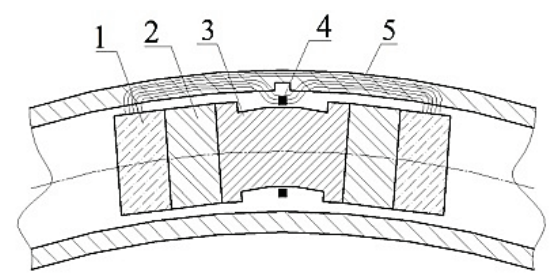

Figure 1 Principle and structure of magnetic flux leakage probe: 1 - armature, 2 - magnet, 3 - magnetic rubber, 4 - sensor, 5 - spiral heat transfer tube

The magneto-sensitive sensors commonly used for magnetic flux leakage detection include induction coil, hall element, etc. Compared with hall element, the biggest advantage of induction coil is that it can ensure the circumferential coverage of the heat exchange inspected tube. The designed detection device chooses the induction coil with various forms to fit different detection requirements as the magnetic sensor. The array patch coil has the advantages of spatial resolution and sensitivity to corrosion in the local area of heat exchanger. The differential coil has the advantages of reducing noise and increasing sensitivity. Therefore, the designed detection device combines the differential coil with the patch coil, and its distribution is shown in Fig. 2. The signal line is drawn through the outlet slot processed by magnetic rubber, magnet and armature.

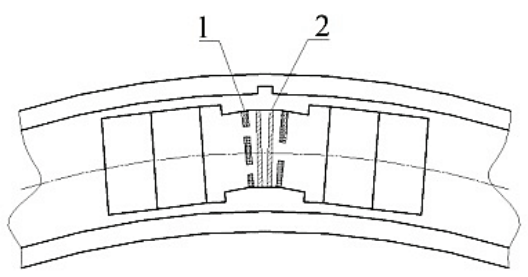

Figure 2 Detection coil arrangement: 1 - array patch coil, 2 - differential coil

\section{MAGNETIC CIRCUIT CALCULATION OF DETECTION PROBE}

In this paper, the axial magnetization method is adopted, and a high coercivity rare-earth magnet, $\mathrm{Nd}-\mathrm{Fe}$ $\mathrm{B}$, is used as the excitation source. In order to develop the performance of materials, the operation point should be chosen near the maximum magnetic energy point or the maximum useful recovery energy point; the magnetic circuit should also be selected reasonably.

\subsection{Design Scheme of Magnetic Circuit}

According to the structure of the detection probe shown in Fig. 1, the magnetic field characteristic parameters can be obtained directly by calculating the excitation circuit with the magnetic conductance method.

(1) Measured wall parameters

The tested objects are small diameter spiral heat exchanger tubes with inner diameter of $14 \mathrm{~mm}$ and steel tubes with wall thickness of $2.5 \mathrm{~mm}$. Outer diameter $D=$ $0.019 \mathrm{~m}$, inner diameter $d=0.014 \mathrm{~m}$, wall thickness $t=$ $0.0025 \mathrm{~m}$, then tube wall sectional area $A_{Z}$ :

$$
A_{z}=\frac{\pi\left(D^{2}-d^{2}\right)}{4}=\frac{3.14 \cdot\left(0.019^{2}-0.014^{2}\right)}{4}=1.3 \times 10^{-4} \mathrm{~m}^{2}
$$

\section{(2) Material of detection probe}

The rare earth permanent magnet, Nd-Fe-B is chosen as the excitation source, the armature is made of $\mathrm{Mn}-\mathrm{Zn}$ ferrites with high permeability. The magnetic rubber rollers choose the soft magnetic rubber made by magnetic powder made of Ni-Zn ferrites and $\mathrm{Mn}-\mathrm{Zn}$ ferrites, which has high magnetic conductivity and physical and mechanical properties, as the intermediate connector between two ends of the excitation source permanent magnets.

(3) Selection of operation point

The operation point of soft magnet is generally on the magnetization curve of the first quadrant of $B-H$ coordinate plane, and the operation point of permanent magnet is generally on the demagnetization curve of the second quadrant of $B-H$ coordinate plane [16]. In order to meet the requirement of magnetic flux stability, the operation point of the magnet should be near the maximum magnetic 
energy product point. According to the demagnetization curve of N48 in Fig. 3, the maximum magnetic energy product $(\mathrm{BHm})$ of $\mathrm{N} 48$ is $47.51 \mathrm{MGsOe}$ at $20{ }^{\circ} \mathrm{C}$, corresponding to $B d=7.02 \mathrm{kGs}$ and $H d=6.76 \mathrm{kOe}$. Therefore, in order to meet the requirements of magnetic field stability and uniformity, the working point of permanent magnet should be chosen at the intersection of the load line and the demagnetization curve at $20^{\circ} \mathrm{C}$. The calculated data of this point are $B m=6.9 \mathrm{kGs}, H m=6.8$ $\mathrm{kOe}$, and magnetic energy product $\mathrm{BHm}=46.92 \mathrm{MGsOe}$.

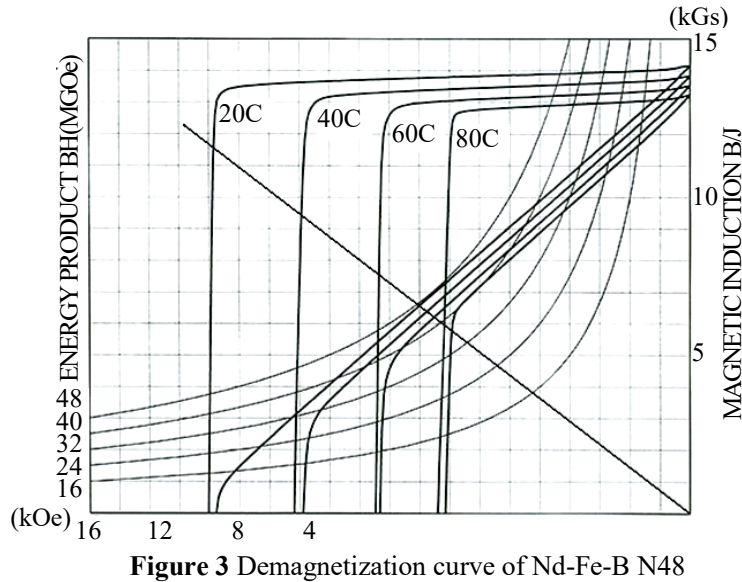

\subsection{Magnetic Circuit Calculation}

The magnetic permeability method is used to calculate the leakage coefficient $k_{f}$. Firstly, equal the magnetic circuit to electric circuit, then calculate each part of permeance of the magnetic circuit. And then $k_{f}$ is calculated according to Kirchhoff equations [16, 17]. The designed excitation magnetic circuit can be equivalent to the equivalent magnetic circuit shown in Fig. 4. In Fig. 4, magnetoresistance $R$ is used, where $R=1 / G$. The length of the magnetic circuit along the inner and outer surfaces is different. Generally, the geometric center line of the magnetic circuit is taken as the average length of the magnetic circuit in calculation.

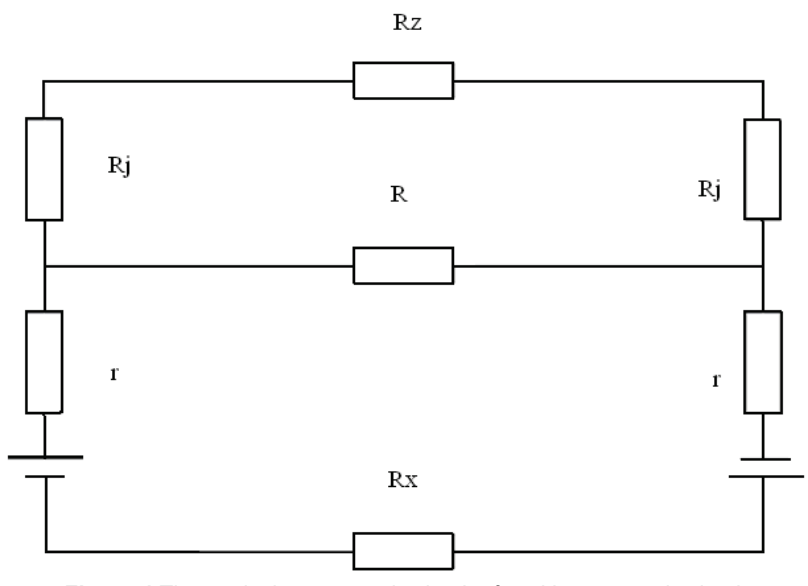

Figure 4 The equivalent magnetic circuit of exciting magnetic circuit

1) Internal permeability of heat exchange tube

$G_{z}\left(G=\frac{1}{R}\right)$ by $B=\mu_{0} \mu H$
Have to $H_{z}=\frac{B_{z}}{\mu_{0} \mu_{z}}$

$r_{z}=\frac{L_{z}}{\mu_{0} \mu_{z} A_{z}}$

$G_{i}=\frac{\Phi_{i}}{F_{i}}=\frac{B_{i} A_{i}}{H_{i} L_{i}}=\sum_{j} \frac{\Delta A_{i j}}{L_{i j}} \mu_{0}=\mu_{0} \sum_{i} \frac{\Delta V_{i j}}{L_{i j}^{2}}$

$G_{z}=\mu_{0} \cdot \mu_{z} \cdot \frac{A_{z}}{L_{z}}$

2) Internal permeability of magnetic rubber rollers $G_{j}$

$$
G_{j}=\mu_{0} \cdot \mu_{j} \cdot \frac{A_{j}}{L_{j}}
$$

3) Permeability of the air gap $G_{g}$

The radial flux density of the cylinder is not uniform, that is, $B$ is a function of radius $r$, but the flux density along the direction of the cylinder is uniform. In the air gap on the surface of a cylinder, the total flux passing through the cylinder surface of any radius is equal, i.e.:

$\Phi_{g}=r \alpha W B(r)$

Then defined by the magnetic motive force we can get that:

$F_{g}=\int_{r}^{r+L_{g}} H(r) \mathrm{d} r=\int \frac{\Phi_{g}}{\mu_{0} r \alpha W} \mathrm{~d} r=\frac{\Phi_{g}}{\mu_{0} \alpha W} \ln \frac{r+L_{g}}{r}$

Therefore,

$G_{g}=\frac{\Phi_{g}}{F_{g}}=\frac{\mu_{0} \alpha W}{\ln \left(1+\frac{L_{g}}{r}\right)}$

Through the above calculation process, $k_{f}$ is calculated by successive approximation method, and then the size of magnet, magnetic rubber roller and armature can be obtained by calculation, as shown in Tab. 1. This magnetization structure can make the steel tube with wall thickness less than $2.5 \mathrm{~mm}$ reach local magnetic saturation, so that the leakage of magnetic field at the defect can reach the maximum.

Table 1 Size of magnet, magnetic rubber rollers, armature

\begin{tabular}{|c|c|c|c|}
\hline & \multirow{2}{*}{ Materials } & \multicolumn{2}{|c|}{ Size / mm } \\
\hline & & Diameter & Length \\
\hline Magnet & Nd-Fe-BN48 & 12 & 10 \\
\hline $\begin{array}{c}\text { Magnetic } \\
\text { rubber rollers }\end{array}$ & $\begin{array}{l}\text { Magnetic powder made of Ni-Zn } \\
\text { ferrites and } \mathrm{Mn}-\mathrm{Zn} \text { ferrites }\end{array}$ & 10 & 20 \\
\hline Armature & Mn-Zn ferrites & 12 & 10 \\
\hline
\end{tabular}

\subsection{Finite Element Simulation}

The solid modeling method is adopted. According to the designed detection structure, the finite element analysis software is applied to carry out 3D simulation. In fact, the defects of spiral heat exchanger tube are mainly caused by 
corrosion. Taking the inner wall defect as the research object, the corrosion pit is simplified to the inner wall cylindrical defect to establish the model for the convenience of quantitative study and finite element analysis of the defect. Fig. 5 shows the three-dimensional finite element model and grid division (take the cylindrical defect on the inner wall with a diameter of $1.6 \mathrm{~mm}$ and a depth of $60 \%$ of the wall thickness of the spiral heat exchange tube as an example), in which the upper half of the spiral heat exchange tube and the surrounding air are set to be hidden.

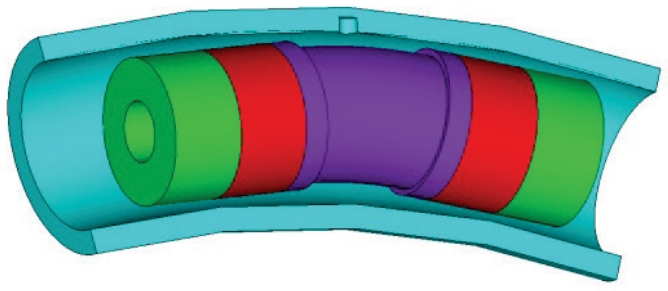

(a) Finite element model

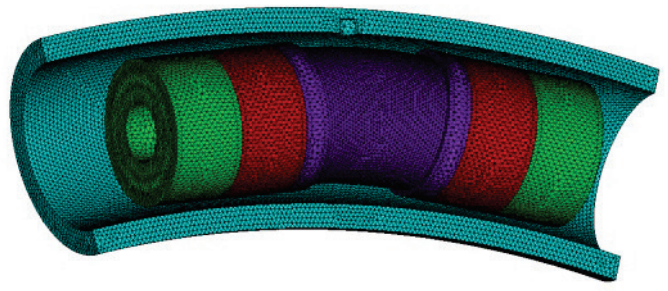

(b) Meshing

Figure 5 Finite element model and meshing

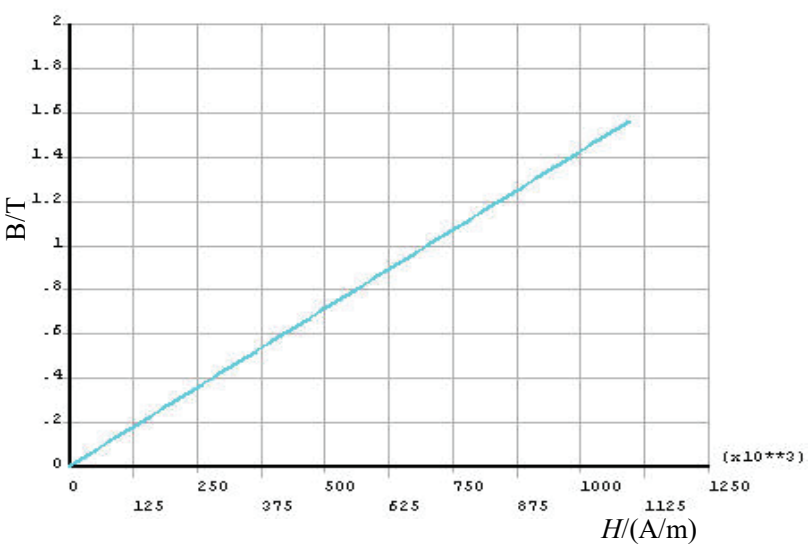

Figure 6 The $B-H$ curve of permanent magnet

In the established model, the permanent magnet is the excitation source and the load of the system. Its magnetic characteristics are defined in the material description. The $B-H$ curve of the permanent magnet is shown in Fig. 6. In the finite element software, the selected solver is sparse matrix solver, and the convergence condition is the default setting of FEM software, L2 norm $\|\{\boldsymbol{R}\}\|_{2}=\left(\sum \boldsymbol{R}_{i}^{2}\right)^{\frac{1}{2}}$. The cylindrical defects on the inner wall with the diameter of $1.6 \mathrm{~mm}$ and depths of $20 \%, 40 \%, 60 \%$ and $80 \%$ of the wall thickness respectively of the spiral heat exchanger tube are taken as the research objects for modelling and simulation analysis (in Fig. 7), and the magnetic induction intensity component on the corresponding path is extracted to obtain the simulation data at different depths of the cylindrical defects with a lift off value of $1 \mathrm{~mm}$. Fig. 8 shows the distribution of magnetic induction intensity components of magnetic field leakage.

It can be seen from Fig. 8 that the peak value of magnetic field leakage increases with the increase of defect depth (20\% wall reduction - $80 \%$ wall reduction). This is consistent with the results of relevant literature [18-20]. And the designed detection structure can detect the defect of $20 \%$ wall reduction, which is verified by simulation experiment.

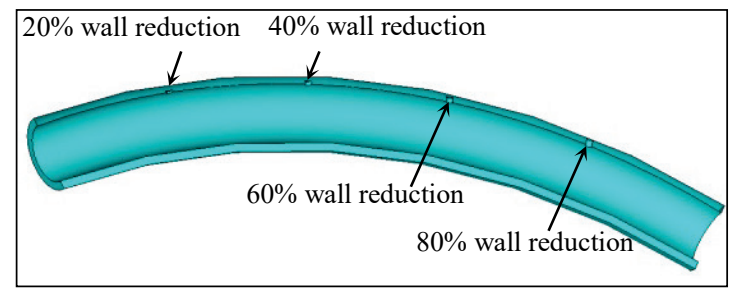

Figure 7 Defect distribution diagram

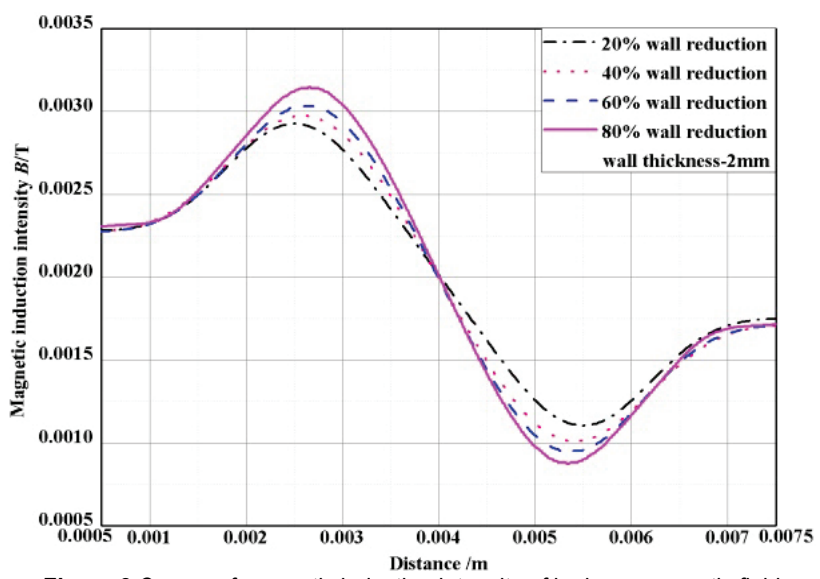

Figure 8 Curves of magnetic induction intensity of leakage magnetic field

\section{STRUCTURAL DESIGN FOR DETECTION DEVICE 4.1 Structural Design for Detection Probe}

Fig. 9 shows the detection probe which is composed of four parts: the intermediate connector, the magnetizers arranged coaxially at both ends of the intermediate connector in turn, the steel ball support body, and the end connector.

(1) The magnetizers include circumferential armature, magnet and steel tube cylinder, which are set on the circumferential axis. The steel tube cylinder is used to protect the magnet and armature. The end surface of the magnet is processed into a ladder shape to make sure that it can be stuck in another inner ladder shape of the steel tube cylinder. Then, the magnet is firstly loaded into one end of the steel tube cylinder, after that the armature is inserted into the steel tube. Magnets, armature and steel tube cylinders are positioned together through the connectors to form an independent whole.

(2) Each steel ball support body consists of two splints and a circle of steel beads between them. The splints I and II used to fix the middle beads are fastened together to form a ring groove for holding the beads which are used to contact the inner wall of the pipe to promote the transmission of the detection probe. 
(3) The intermediate connector is composed of magnetic rubber rollers and magnetic sensitive detection elements mounted on the magnetic rubber rollers. The magnetic rubber roller with the narrower middle part to provide space for the installation of magnetosensitive element and signal circuit is used for intermediate connection and magnetic conductivity. The magnetic sensitive detection element is used by combining differential coil and patch coil. The intermediate connector is bonded to the magnetizer at both ends of the connector in the same way as the magnetized magnet and the end face of the steel tube cylinder are bonded to the end face of the magnetic rubber rollers.

(4) On the one hand, the end connector located at the two ends of the detection probe fits with the armature of the magnetizers to fix the steel ball support body, and on the other hand, it is connected with the probe driving mechanism.

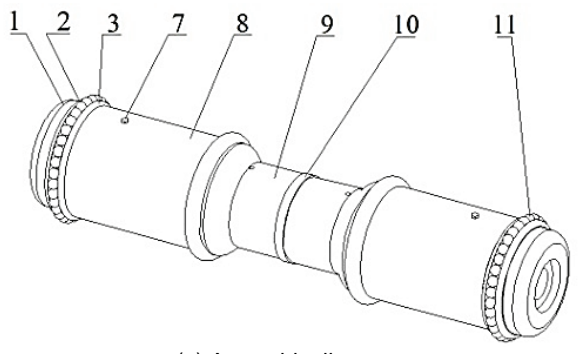

(a) Assembly diagram

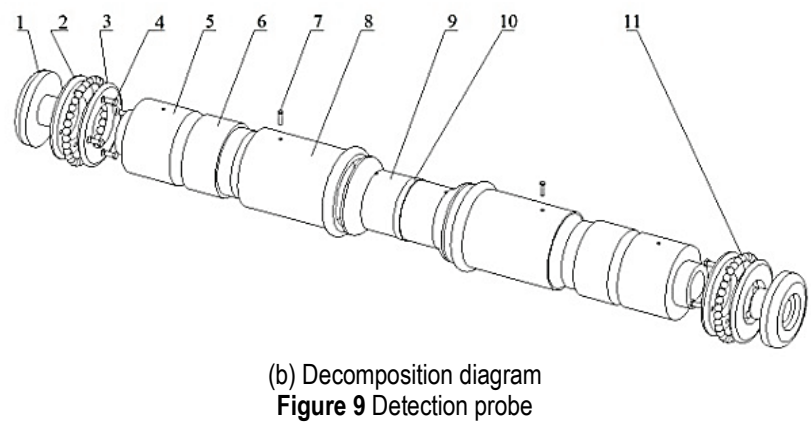

\subsection{Driving Mechanism of Detection Probe}

The probe driving mechanism includes rotating pulse encoder, cable locator, control box, cable reel, stepping motor, a group of auxiliary pulleys, and hose cable, as shown in Fig. 10. The control box is equipped with a cable reel for controlling the lifting of hose cables connected with the detection probe, and a cable locator for wrapping hose cables around the cable reel. The signal processing computer is used to control the stepper motor which is used to control the rotation of the cable reel. A set of auxiliary pulleys are installed on the control box to conduct the hose cable to the cable reel tangentially installed with the rotary encode and to the interface of the signal-processing computer connected with the rotary pulse encoder.

\subsection{Integral Structure Design for Detection Device}

The designed magnetic leakage inspection device for small diameter ferromagnetic spiral heat exchanger tube is shown in Fig. 11, which mainly includes the detection probe and probe driving mechanism mentioned above.
During the implementation of the detection, the detection probe is used to realize excitation and signal acquisition of small-diameter spiral heat exchange tube, and the probe driving mechanism ensures that the detection probe can detect at a long distance with a uniform speed in the spiral heat exchanger tube. For one thing, the end connector located at both ends of the detection probe is connected with the cable connector of the probe driving mechanism (the cable connector is installed on the hose cable), which is used to connect the detection probe with the hose cable of the probe drive mechanism, for another thing, it is used to fix the steel ball support body by cooperating with the armature of the magnetizes.

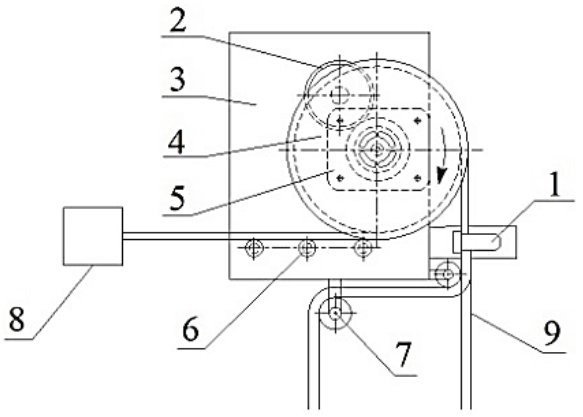

(a) Two-dimensional diagram

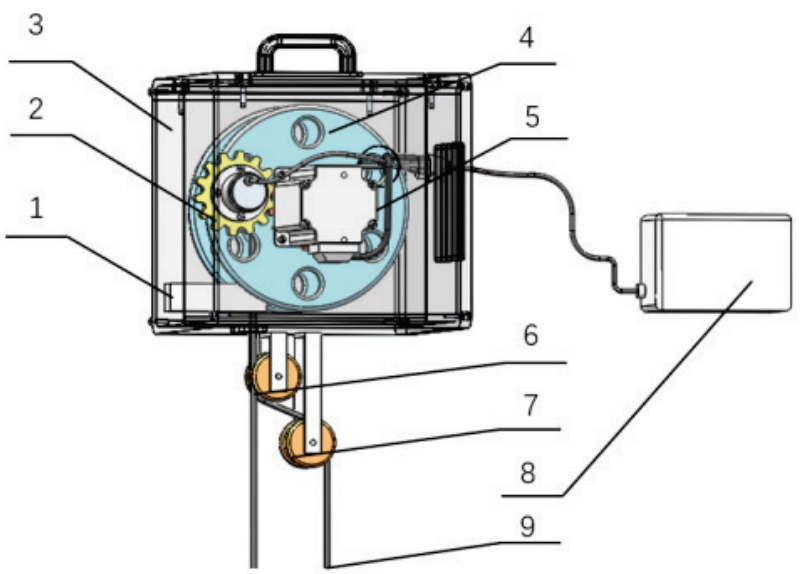

(b) Three-dimensional diagram

Figure 10 Probe driving mechanism: 1 - cable locator, 2 - rotary pulse coder, 3 control box, 4 - cable reel, 5 - stepper motor, 6 - auxiliary pulley I, 7 - auxiliary pulley II, 8 - signal processing computer, 9 - hose cable

\section{DETECTION METHOD FOR SERIES AND PARALLEL CONNECTION}

In the process of magnetic flux leakage testing for small diameter helical heat exchanger tubes, the length of a single helical heat exchanger tube in the helical heat exchanger is tens of meters, or even hundreds of meters, and the number of helical heat exchanger tubes is huge. If only one detection probe is used for each detection, the detection efficiency is low. The detection probes designed in this paper are connected in series and parallel in order to be placed in a spiral heat exchange tube, forming a group of detection probes in series. Then, to improve the detection efficiency multiple groups of detection probes in series are placed in each spiral heat exchange pipe to form a series and parallel combination to test multiple spiral heat exchange pipes at the same time. The detection process is shown in Fig. 12. 


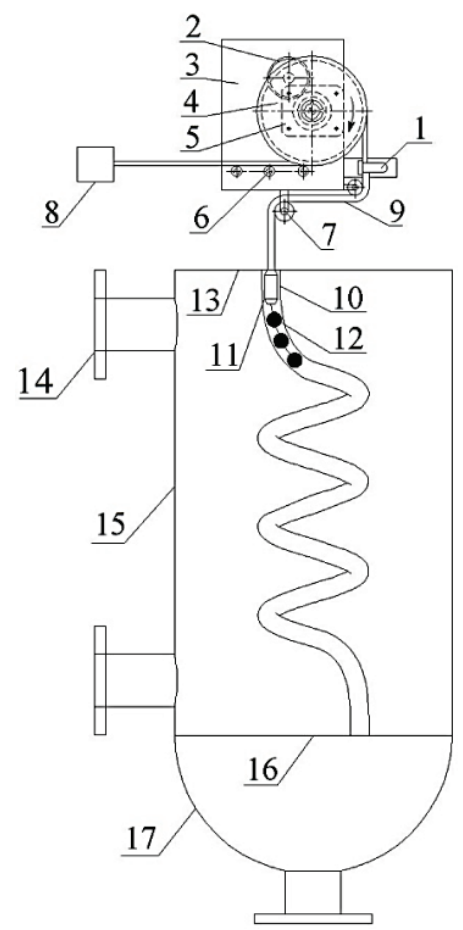

(a) Two-dimensional diagram

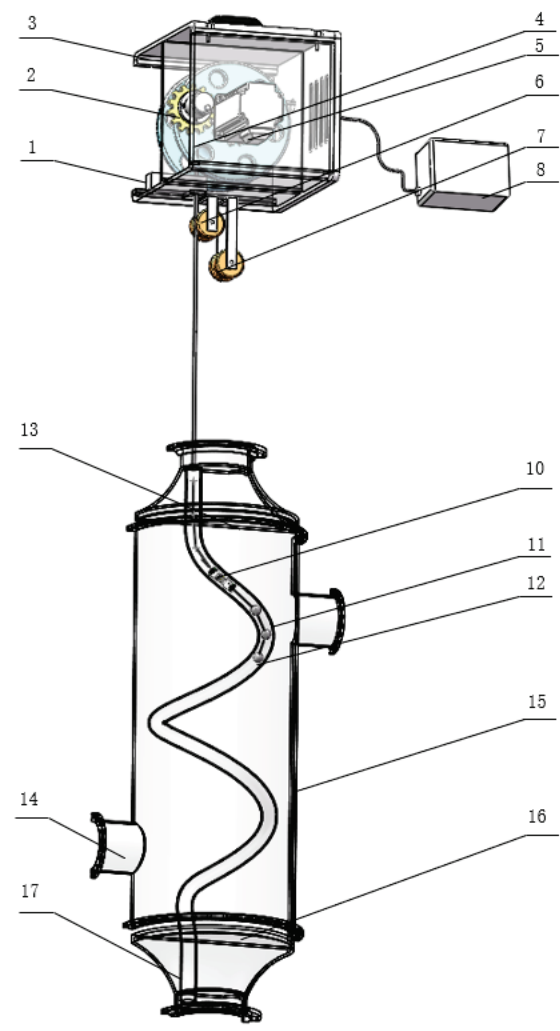

(b) Three-dimensional diagram

Figure 11 Magnetic leakage detection device for small diameter ferromagnetic spiral heat exchange tube: 1 - cable locator, 2 - rotary encoder, 3 - control box, 4 - cable reel, 5 - stepper motor, 6 - auxiliary pulley I, 7 - auxiliary pulley II, 8 -

signal processing computer, 9 - hose cable, 10 - inspected pipeline, 11 detection probe, 12 - steel ball, 13 - upper tube plate, 14 - flange, 15 - tube box, 16 - lower tube plate, 17 -head

Series detection process:

Each $N$ detection probe with a length of $L$ is connected in series with a hose cable. A number of steel balls are connected under the lowest detection probe to form a series detection probe group. Wrap the hose cable at the upper end of the detection probe group on the cable reel, and the stepper motor controls the cable reel to rotate.

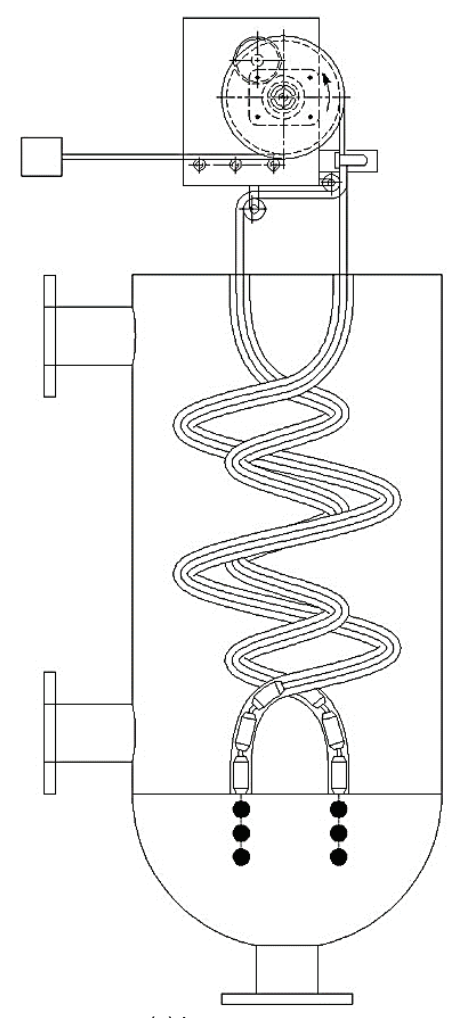

(a) lower process

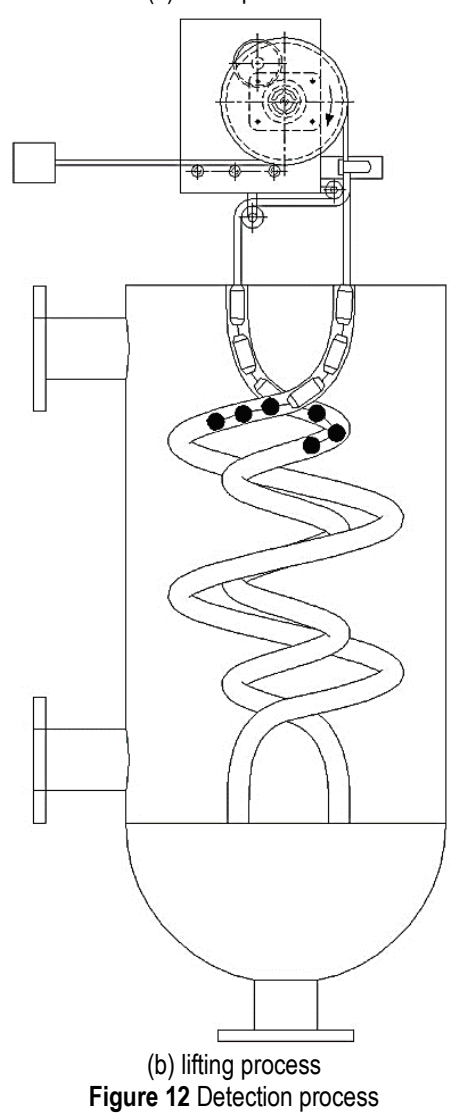

Fig. 12a shows that the serial detection probe group transfers to a lower level to the bottom end of the spiral heat exchange tube under the action of the ball's own gravity. After it comes to the bottom end, the detection probe group is driven up by rotating the cable reel, the distance of $N \times L$ can be detected by lifting distance $L$ each time. In order to avoid repeated detection of the same defect by multiple detection probes, the distance of $(N-$ 
1) $L$ is rapidly raised after the distance of $L$ is raised at a slow speed, and no detection is conducted in this process. Then repeat the above process of slowly lifting $L$ and rapidly lifting $(N-1) L$ distance, and so on, until it is lifted to the upper end of the spiral heat exchange tube, and the detection of a spiral heat exchange tube is completed, as shown in Fig. 12b.

Parallel detection process: The detection probe groups in series wounded on the cable coil side by side through the corresponding hose cables to ensure the synchronization of the motion state of each hose cable are placed at the bottom of different spiral heat exchanger tubes. Repeat the process of slowly raising $L$ and rapidly raising $(N-1) L$ distance in series detection can carry out flux leakage detection for multiple helical heat exchanger tubes at the same time to realize the detection of series-parallel mixing.

In the process of series and parallel lifting detection, the speed of stepper motor and the distance of each lifting can be controlled by computer. And in the process of serial and parallel detection of probes, each probe is connected with a separate signal line to output the corresponding detection signal to the signal processing computer. Through the analysis of computer software, the detection signal can be inverted, so as to realize the localization of the defects on the spiral heat exchanger tube and subsequent qualitative and quantitative detection.

\section{CONCLUSIONS}

(1) The middle connector of the probe of the traditional magnetic flux leakage detection device for heat exchange tube is armature, which makes the probe unable to bend, so it can only carry out the magnetic flux leakage detection on the large diameter heat transfer straight tube. However, the proportion of spiral tube heat exchanger is increasing and there is no magnetic leakage detection device for small diameter spiral tube. Based on the calculation of the magnetic circuit design of the detection probe, this work designs a matching detection probe and designs the connector in the middle of the detection probe into a magnetic rubber roller with large flexibility and small bending stiffness, which not only has the function of magnetic conduction, but also meets the passing requirements of small diameter helical heat exchanger tubes with minimum inner diameter of $14 \mathrm{~mm}$. The detection device can be used for magnetic flux leakage detection of spiral heat exchange tube with diameter of more than $14 \mathrm{~mm}$.

(2) The steel ball support body is arranged on the probe of the detection device, and it rolls on the inner wall of the spiral heat exchange tube to avoid the friction between the probe and the inner wall of the tube, which may cause damage to the detection probe. On the other hand, the rolling of steel beads in the spiral heat exchanger tube is beneficial for the detection probe to move forward. The steel ball support body is compressed and fixed through the threaded connection between the end connector and armature. When the steel ball support body is damaged by wear, it can be removed and replaced easily.

(3) In the process of magnetic flux leakage detection for small diameter spiral heat exchanger tubes, the probe should move forward smoothly in the spiral heat exchanger tubes, while the single spiral heat exchange tube in the heat exchanger is generally relatively long, and the number of spiral heat exchange tubes is large, if only one detection probe is used for each detection, the detection efficiency is low. In this work, multiple detection probes are put together in series to be placed in a spiral heat exchange tube to form a group of detection probes in series. Then, multiple groups of detection probes in series are placed in each spiral heat exchange pipe, forming a series-parallel combination, which can detect multiple spiral heat exchange pipes at the same time and improve the detection efficiency greatly.

\section{Acknowledgements}

This work was sponsored by the National Natural Science Foundation of China (51607035, 51774091, 51974327) and China Scholarship Council and China Postdoctoral Science Foundation (2018M641804, 2019M661248, 2018T110268) and Heilongjiang Youth Innovation Talents of Ordinary Undergraduate Colleges and Universities (UNPYSCT-2018046)and Daqing guiding science and technology planning project (zd-201920) and Natural Science Foundation of Heilongjiang province (LH2019E018) and Heilongjiang Postdoctoral Research Foundation (LBH-Q18029) and Heilongjiang Postdoctoral Foundation (LBH-Z16040) and Science and Technology Project of China Petroleum and Chemical Industry Association (2017-11-04) and Research start-up fund of Northeast Petroleum University (rc201732). All these are gratefully appreciated.

\section{REFERENCES}

[1] Mellouli, S., Askri, F., Dhaou, H., Jemni, S. A., \& Nasrallah, B. (2010). Numerical simulation of heat and mass transfer in metal hydride hydrogen storage tanks for fuel cell vehicles. International Journal of Hydrogen Energy, 35(4), 16931705. https://doi.org/10.1016/j.ijhydene.2009.12.052

[2] Srisawad, K. \& Wongwises, S. (2009). Heat transfer characteristics of a new helically coiled crimped spiral finned tube heat exchanger. Heat and Mass Transfer, 45(4), 381-391.https://doi.org/10.1007/s00231-008-0441-1

[3] Zhao, Q., Liu, F., Liu, C. W., Tian, M. C., \& Chen, B. M. (2017). Influence of spiral pitch on the thermal behaviors of energy piles with spiral-tube heat exchanger. Applied Thermal Engineering, 125(10), 1280-1290. https://doi.org/10.1016/j.applthermaleng.2017.07.099

[4] Bao, Z. W., Liu, L., \& Yuan, S. Y. (2015). Numerical Analysis and Optimization of Metal Hydride Reactors Incorporating Helical Coils during Adsorption. Journal of Sichuan University (Engineering Science Edition), 47(5), 185-190. https://doi.org/10.15961/j.jsuese.2015.05.027

[5] Liu, J. J., Liu, Z. C., \& Liu, W. (2015). 3D Numerical Study on Shell Side Heat Transfer and Flow Characteristics of RodBaffle Heat Exchangers with Spirally Corrugated Tubes. International Journal of Thermal Sciences, 89(3), 34-42. https://doi.org/10.1016/j.ijthermalsci.2014.10.011

[6] Xu, S. J., Gai, X. C., \& Wang, N. (2015). The Using of Screw Tube Heat Exchanger in Petrochemical Engineering. Shandong Chemical Industry, 44(4), 104-106. https://doi.org/10.19319/j.cnki.issn.1008021x.2015.04.038

[7] Ohtani, T., Kawashima, K., Drew, M., \& Guagliard, P. (2007). Nonlinear Acoustic Evaluation of Creep Damage in 
Boiler Heat Exchange Tubes. Japanese Journal of Applied Physics, 46(7), 4577-4582. https://doi.org/10.1143/JJAP.46.4577

[8] Trobradovic, N. \& Naydenova, Z. (2012). New Fast NonDestructive Inspection Technique of Heat Exchanger Tubes Applying Acoustic Pulse Reflectometry (APR). CrSNDT Journal, 2(2), 23-29.

[9] Dai, G., Cui, W., \& Yang, Z. J. (2010). Magnetic Concentracting in Numerical Simulation of 3D Finite Element of Magnetic Flux Leakage Testing of Heatexchange Tube. Journal of pressure vessel, 27(4), 23-26. https://doi:10.3969/j.issn.1001-4837.2010.04.006

[10] Qi, P., Chen, D. Z., \& Cui, H. Y. (2016). Simulation for nuclear power plant heat exchange tube eddy current array inspection. Nondestructive Testing, 38(11), 53-56. https://doi:10.11973/wsjc201611012

[11] Cong, M., Wu, X. J., Sun, P. F., \& Wu, L. F. (2014). Simulation Research on Defect Detection of Heat Exchanger Tubes Based on Torsional Guided Wave. Journal of pressure vessel, 31(5), 65-68.

[12] Cui, W., Song, R. X., Feng, Z. M., Zhang, Q., \& Ma, Z. P. (2019). Study on Crack Growth of Ferromagnetic Pipeline Weld based on Magnetic-Structural Coupling. Tehnicki Vjesnik-Technical Gazette, 26(2), 420-427. https://doi.org/10.17559/TV-20180617051005

[13] Kandroodi, M. R., Araabi, B. N., Bassiri, M. M., \& Ahmadabadi, M. N. (2017). Estimation of depth and length of defects from magnetic flux leakage measurements: verification with simulations, experiments, and pigging data. IEEE Transactions on Magnetics, 53(3), 1-10. https://doi.org/10.1109/TMAG.2016.2631525

[14] Antipov, A. G. \& Markov, A. A. (2018). 3D simulation and experiment on high speed rail MFL inspection. $N d t \& E$ International, 98(9), 177-185. https://doi.org/10.1016/j.ndteint.2018.04.011

[15] Hosseingholizadeh, S., Filleter, T., \& Sinclair, A. N. (2019). Evaluation of a Magnetic Dipole Model in a DC Magnetic Flux Leakage System. IEEE Transactions on Magnetics, 55(4), 1-7. https://doi.org/10.1109/TMAG.2019.2897669

[16] Wang, Y. Z. (1991). Practical magnetic circuit design. Tianjin: Tianjin science and technology press, 45-46.

[17]Cai, Y. Y. (2000). Circuits and magnetic circuits (volume II). Beijing: Higher education press, 89-94.

[18] Cui, W., Wang, K., Zhang, Q., \& Zhang, P. (2017). A Recognition Algorithm to Detect Pipe Weld Defects. Tehnicki Vjesnik-Technical Gazette, 24(6), 1969-1975. https://doi.org/10.17559/TV-20170523211205

[19] Chang, Y., Jiao, J. P, Li, G. H, He, C. F, \& Wu, B. (2018). Influencesand Optimization of Excitation Structure ofMagnetic Flux Leakage Sensor. Journal of Mechanical Engineering, 54(24), 7-17. https://doi.org/10.3901/JME.2018.24.007

[20] Yan, S., Chao, Z., Rui, L., Cai, M. L., \& Jia, G. W. (2015). Theory and application of magnetic flux leakage pipeline detection. Sensors, 15(12), 31036-31055 https://doi.org/10.3390/s151229845

\section{Contact information:}

Wei CUI, associate professor

1) Northeast Petroleum University,

Daqing high-tech development zone university street,

No. 99, Daqing City, Heilongjiang Province, China

2) Nanyang Technological University,

50 Nanyang Avenue, Singapore

E-mail: cuiweivv@126.com

Yuhang ZHANG, postgraduate

Northeast Petroleum University,

Daqing high-tech development zone university street,
No. 99, Daqing City, Heilongjiang Province, China

E-mail: 120394261@qq.com

\section{Ziming FENG, professor}

(Corresponding author)

Northeast Petroleum University,

Daqing high-tech development zone university street,

No. 99, Daqing City, Heilongjiang Province, China

E-mail: xueyuanfzm@163.com

Chaodong TAN, associate professor

(Corresponding author)

China University of Petroleum (Beijing),

Changping district, Fuxue road No. 18, Beijing, China

E-mail: tanchaodong@cup.edu.cn

Decheng LENG, engineer

Daqing Petrochemical Company,

Longfeng district, Chemical road No. 90,

Daqing City, Heilongjiang Province, China

E-mail: 44319552@qq.com

Qiang ZHANG, associate professor

Northeast Petroleum University,

Daqing high-tech development zone university street No. 99,

Daqing City, Heilongjiang Province, China

E-mail: tical2012@163.com 